\title{
ECO-TOURISM AND THEORETICAL-PRACTICAL ASPECTS OF SUSTAINABLE PLANNING
}

\section{MAIA AZMAIPARASHVILI}

\author{
Dr., Associate professor
}

Gori State Teaching University,

European University, Georgia

azmaiparashvili.maia@eu.edu.ge

\begin{abstract}
Sustainable tourism development is a fundamental concept of tourism planning. Optimal use of resources helps to preserve natural treasures. Businesses are required to have high standards of accountability in order to avoid adverse environmental impacts in a competitive environment. Less attention is paid to the problems of destinations in general and its sustainability in particular. Innovative tourism management is increasingly focused on local destination management and its sustainability. In this paper, we discuss the problems of destination sustainability on the example of protected areas. We analyzed visitor statistics, processed visitor satisfaction survey, revenue and the impact of tourism sustainability on the quality of the destination. In addition, the paper covers the problems identified in terms of sustainable development, such as ensuring the sustainability of the destination, sustainable maintenance and development dependence on its management. Tourism and environmental conditions are interrelated. The environment contains many elements. The most important factor in achieving sustainable development is the development and management of tourism in a way that does not harm the environment. Ecologically correct planning of tourism should be well aware of the potential impacts that follow the development of tourism. Sustainable development means balancing economic progress, social justice and protection of the physical and natural environment. The principle of sustainability includes the ecological, economic and socio-cultural aspects of tourism development, so it is necessary to balance all three directions to guarantee the long-term sustainability of the destination.
\end{abstract}

KEYWORDS: PLANNING, SUSTAINABLE, ECONOMY, DESTINATION, ECOTOURISM COUNTRY.

For citation: Azmaiparashvili, M., (2021). Eco-Tourism and Theoretical-Practical Aspects of Sustainable Planning. Globalization and Business. 12, 186-190. https://doi.org/10.35945/gb.2021.12.026

\section{INTRODUCTION}

The growing role of tourism in sustainable development and the world economy has raised the new question of whether it is possible to develop the tourism sector in the light of key areas of sustainability (Pigram \& Wahab, 2005). Over the years, the above concepts have come together and resulted in the concept of sustainable tourism development, which combines four main approaches: 1. Protecting the heritage, environment and biodiversity created by mankind 2 . Protecting vital ecological processes 3. Promoting public inclusion 4. Creating productivity (Florek, 2012).

Sustainable tourism development is a fundamental concept of tourism planning. This concept envisages the preservation of natural, cultural and other resources for their continued use in the future in a way that benefits the community even today. One of the essential benefits of tourism, in the case of its conceptual development, is that it can subsidize the protection of natural and cultural resources. Thus: tourism is an important means of ensuring the environment; Tourism is an important means of protecting cultural heritage. Optimal use of resources helps to preserve natural treasures. With respect to the socio-cultural identity of the host societies, it is possible to establish inter-cultural relations, which in turn implies the sharing of cultural heritage and traditions. In addition, the sustainable development of tourism serves to improve the social conditions of the society, by increasing economic activities, redistributing wealth, eradicating poverty or creating jobs. Constant monitoring of tourist satisfaction is of great importance, for the effective implementation of which the diversity of the participating parties is important. Businesses are required to have high standards of accountability in order to avoid adverse environmental impacts in a competitive environment. As for new trends in sustainable tourism development, ecotourism is becoming popular in the world, which involves traveling in nature and redistributing financial resources to the local community (Florek, 2012). The main idea of all the abovementioned approaches is to reduce the environmental impact and to provide voluntary financial resources to different societies in order to increase development opportunities. 
The history of protection of natural territories in Georgia begins centuries ago. As early as the eleventh century, Queen Tamar issued a royal decree to protect some territories. Five hundred years later, Vakhtang VI's "Code of Laws" referred to the Koruli area as a place of protection where it was forbidden to cut down trees and walk, and the area was guarded by guards. The first official reserve was established later in 1912 in Kakheti and was called Lagodekhi Reserve. During the 20th century, other nature reserves and protected areas were gradually established throughout Georgia (Kikodze \& Gokhelashvili, 2007). In 1996, the Parliament of Georgia took into account the importance of the unique and unique natural-cultural environment of our country and adopted the "Law on the System of Protected Areas". This law creates a legal basis for the establishment of protected areas, the purpose of which is to protect the country's remarkable natural environment and precious cultural heritage. Georgia has legalized the categories of protected areas in accordance with international criteria and norms and the procedure for establishing which is based on the recommendations of the World Conservation Union (IUCN).

The existence of a network of national parks and other protected areas undoubtedly contributes to the development of tourism in Georgia. It should be noted that most of the protected areas (70-80\%) are covered with forests, namely oaks, beeches, pines and spruces. There are many historical and cultural monuments in national parks, which organically merge with natural landscapes, most of them are ancient and located in precious forests (Gigauri \& Supatashvili, 2007). Protected areas today play a key role in protecting Georgia (and not only Georgia) biodiversity, natural heritage. In addition, protected areas are distinguished by their unique natural-aesthetic characteristics. The aim of the paper is to use the example of protected areas to study how visitors perceive the diversity of the landscape and what role perceptual resources can play in the scheme of protected areas planning and management improvement. The paper also focuses on visitor statistics for protected areas, visitor satisfaction surveys, tourism revenues, and the impact of tourism sustainability on destination quality.

\section{LITERARY REVIEW}

It can be said that the study of protected areas of Georgia has a long history, the scientific research in this direction was founded by Academician Vasil Gulisashvili, the founder of the Tbilisi Forest Scientific Research Institute. For the first time he studied the spa significance of the forest (1934, 1949), Vladimer Matikashvili (1938) and Giorgi Gigauri have interesting works on the spa significance of the forests of Georgia (1960). A long time has passed since the publication of these works and they have become a bibliographic rarity. The monograph of Giorgi Gigauri and Archil Supatashvili on the spa-recreational-tourist-importance of Georgian forests and the basics of running their farms (2007) is also interesting (published within Protected Areas Development Project). One cannot fail to mention Marina Metreveli Handbook on
Environment and Ecotourism Management (2012), the handbook deals with natural resources, protected areas, environmental policy, principles and characteristics of tourism nature use, etc.

\section{METHODOLOGY}

It is very important for the protected areas to study the opinion of the visitors and to hear constructive criticism from them. This can be done by contacting directly as well as by filling out electronic and printable questionnaires. Visitors fill in registration forms (origin, age, sex, etc.) when visiting protected areas. In visitor centers, these data are collected by the territorial administrations and processed by the Agency of Protected Areas. The selected group is interviewed using an interviewer administered / self-administered (including electronic) questionnaire. We used data obtained from visitor centers for our research. Qualitative research methods are used. The target group and the research area were identified. We analyzed visitor statistics, visitor satisfaction survey, revenue and the impact of tourism sustainability on the quality of the destination. Ensuring the sustainability of the destination, sustainable maintenance and development dependence on its management.

\section{RESULTS AND DISCUSSION}

Questions arise: Who do you involve in the process of developing a strategic vision for the community / destination of the national park? What type of tourism activity would you encourage in a national park and allow to exist? The most common form of protected area organization is the creation of national parks. Parks are created in places where ecosystems, as a result of human agricultural activities, have not yet changed and where the animal / plant world is preserved in its original form, where geomorphology, habitat are of particular interest and landscapes are particularly beautiful. Parks are created by international organizations, based on the decisions of the highest state bodies or in agreement with them. Georgia's biodiversity is important nationally, regionally and globally The Caucasus Ecoregion is one of the two eco-regions recognized by the World Wide Fund for Nature (WWF) as a priority site for conservation based. There are 87 protected areas of five categories in Georgia. It occupies $9.56 \%$ of the total area of the country $(666,107$ ha). In 2019, 1,199,011 visitors visited. Growth compared to the previous year $+8.2 \%$. The share of foreign visitors is $51 \%$. Most visitors visited Kazbegi National Park - 195,228 (16.3\%), Martvili Canyon - 189,894 (15.8\%) and Prometheus Cave - 184,264 (15.4\%). Prometheus, Martvili, Okatsi, Mtirala, Sataplia, Kinchkha waterfalls, the number of foreign visitors to Tusheti, Machakhela and Chachuna protected areas exceeded the number of Georgian visitors. Consequently, the largest number of foreign visitors also visited Prometheus Cave and Martvili Canyon (Table 1).

The number of foreign visitors to the protected areas 
Table 1.

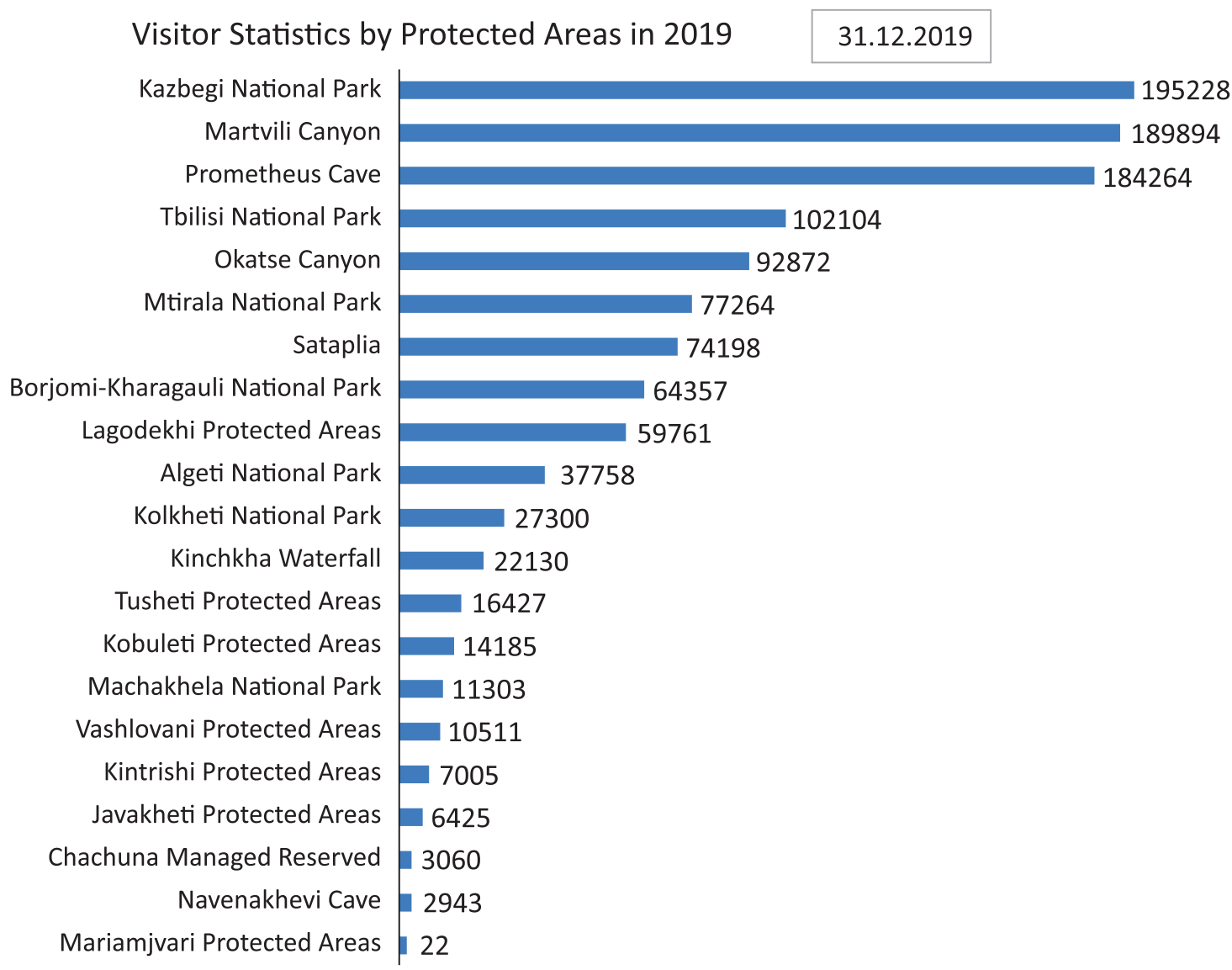

Source: http://apa.gov.ge/ge/statistika/vizitorta-statistika

amounted to 611,989 , an increase of $+15.7 \%$. Foreign visitors predominated: Russians 20.5\%, Jews $12.2 \%$, Poles $7.9 \%$, Germans $7.8 \%$ and Ukrainians 6\%. Revenues from tourism services in protected areas amounted to GEL 9,363,447, an increase of $+11 \%$ over the previous year. Leading in terms of revenue were: Prometheus Cave - 3,738,026 GEL, Martvili Canyon - 2,921,300 GEL, Okatse Canyon - 1,152,511 GEL and Sataplia - 792,030 GEL. (file:///C:/Users/HP/Desktop/2019_ print_GEO.pdf).

In the coming years, the budget for the planned infrastructure projects will be about $212000000 \mathrm{GEL}$, of which 49 $000000 \mathrm{GEL}$ will be from the state budget. The implementation of new projects will significantly contribute to the interest and attraction of visitors; accordingly, the projected number of visitors to the protected areas will increase 5 times and reach 8 million, and the income from ecotourism will reach 58 million GEL. It should be noted that at present, the volume of private investments in the protected areas of Georgia is 142 million GEL. According to the current forecast, by 2030, investments will increase at least 3 times and will reach 429 million GEL.

It is important to analyze the destinations where more visitors were mentioned. In Prometheus Cave, Martvili Canyon and Sataplia, a data research team conducted a survey of visitor satisfaction with Georgian national reserves in July-August 2019. The study included those visitors who visited the Georgian National Reserves and benefited from the services available there. The survey was conducted with
Georgian, English and Russian specialized questionnaires administered by the interviewer. The survey was conducted by 6 interviewers. The survey was conducted on 338 visitors, of which $44 \%$ were Georgian tourists and $56 \%$ were foreign tourists. The mean age of the study group was 44 years, the minimum age was 18 , the maximum age was 70 years. $53.6 \%$ of the participants were male and $46.4 \%$ were female. $92.7 \%$ of the respondents were in the Georgian National Reserve for the first time, $7.3 \%$ for the second and / or more times. For $80 \%$ of foreign citizens, this visit coincided with the first visit to Georgia.

The vast majority of respondents - $88 \%$ - definitely recommend friends to visit Georgia reserves, while $12 \%$ might recommend. To the question "Would you visit the reserve in the future in case of increasing the entrance fee to the reserve (1-3 GEL for a citizen of Georgia, 2-5 GEL for a foreign citizen) in order to improve the service and infrastructure?" I would visit, however, to create discomfort of $32.2 \%$; I would no longer visit $6.2 \%$. Foreign tourists: I would definitely visit $76 \%$; I would visit, however, to create discomfort of $18.5 \%$; I would no longer visit $5.5 \%$. Taking into account all the services, the picture of the evaluation of the points in the reserves, where 10 points correspond to the great satisfaction of the visitor, and 0 dissatisfaction, is as follows: - 10 points - 35.3\%; 9 points $25.8 \%$; 8 points $26.3 \%$; 7 points $7.9 \%$; 6 points $2.7 \% 5$ points $1 \%$. (http://drg.com.ge/team.php).

The ideas of the visitors identified during the research 
are noteworthy, the implementation of which would make the reserve more attractive to visitors: in Martvili it would add chairs where the visitor would be able to relax $20.2 \%$; $23.1 \%$ of visitors think adding food items is important; Also, $36.2 \%$ think that the park area should be expanded and more walking trails should be arranged; $23 \%$ think that up-to-date information on access to services should be available on the Internet; The outer area of the park should be regulated by $8.6 \%$; English language service staff needed to improve $15.7 \%$; It is necessary to arrange a ramp $1.73 \%$; Admission to the park should be $1.73 \%$ free for locals. Prometheus needed to improve the English language level of the service staff by $19.2 \% ; 3.8 \%$ would clear the trail in the cave; View of the river to be available without tickets $3.8 \%$; ATM placement in the cave area - 3.8\%. 6.7\% think that Sataplia's service staff needs to improve their English language skills; Domestic transport to move in the park 6.7\%; More dinosaur skeletons $6.7 \%$; $6.7 \%$ think more extreme entertainment is important (http:// drg.com.ge/team.php).

According to the information received from the Agency of Protected Areas of Georgia, $84 \%$ of the surveyed visitors to the protected areas of Georgia in the summer of 2019 are satisfied. Most of the $88 \%$ of the visitors definitely recommend their friends to visit the protected areas of Georgia. $68.8 \%$ of the respondents assess the attitude of the staff towards the visitor as very friendly. When traveling to protected areas, $88.3 \%$ feel protected.

As of 2020, 240268 visitors visited the protected areas, a decrease of $-80 \%$ over the previous year. The number of foreign visitors to the protected areas was 26,432, with a decrease of $-95.7 \%$. Among foreign visitors, Russians (share $18.7 \%$ ), Germans (share 10.3\%), Jews (share 8\%), Poles (share 6.7\%) and Latvians (share 6.1\%) predominated. The highest number of visitors visited Tbilisi National Park 61,890 (25.8\%), Kazbegi National Park - 28,515 (11.9\%) and Martvili Canyon - 21,489 (8.9\%). Most foreign visitors visited Prometheus - 7,090 (26.8\%), Martvili Canyon - 3,401 (12.9\%) and Kazbegi National Park - 3,390 (12.8\%). The reduced number of visitors was also reflected in the revenues of the protected areas. Revenues from tourism services in protected areas amounted to $899,076 \mathrm{GEL}$, a decrease of $-90.4 \%$ over the previous year. Leading in terms of revenue were: Prometheus Cave - 290,589 GEL, Martvili Canyon - 255,644 GEL, Sataplia - 98,569 GEL and Okatse Canyon - 91,756 GEL. Covid and related regulations have had a significant impact on protected areas, namely: the share of foreign visitors to protected areas has been reduced from $51 \%$ to $11 \%$. The decrease in the number of foreign visitors was $-95.7 \%$, while the decrease in Georgian visitors was $-63.6 \%$. As a result, the share of foreign visitors in the number of visitors to protected areas has decreased.

The situation created by COVID-19 in the spring and summer of 2020 had a significant impact on the development of Georgia's 2020-2030 ecotourism strategy document. The vision is as follows: "By 2030, Georgia will be a leading, ecotourism country in the Caucasus region, which, with its rich living culture and nature, as well as high quality services, will provide ecotourism offers for all four seasons. Ecotourism in Georgia provides an authentic experience for tourists, benefits local communities and significantly contributes to the country's economic well-being; At the same time, it ensures the preservation of natural and cultural heritage and raises environmental awareness among tourists and locals."

There is no doubt that tourism cannot develop in the country without a system of protected areas. The existence of tourism depends on the functioning of ecosystems and the services they offer. Georgia has a colossal potential for tourism development, as it has a variety of natural zones, aesthetically Attractive landscapes, unique flora and fauna untouched by urbanization and cultivation processes, not a small number of relict and endemic species included in the Georgian and International Red Book, protected and developed networks of natural areas. The special attraction of the country for ecotourists is the richness of ethnoculture, the variety of public holidays, customs, crafts, traditional hospitality of the population and a peculiar Georgian cuisine.

Innovative tourism management is increasingly focused on local destination management and its sustainability. Scientists do not argue that destination is the core of tourism. Therefore, it is easy to assess the importance of destination sustainability, what is practically equivalent to tourism sustainability. Nevertheless less attention is paid to the problems of destination in general and its sustainability in particular. One of the important conditions for the organization of ecological-tourism activities is to ensure rational, sustainable nature use in protected areas. In terms of protected areas managed by an approved management plan, if we exclude the issue of IUCN Category VI Protected Areas, there is no legal basis or institution for sustainable management. Ensuring the sustainability, maintenance and development of the destination is even dependent on its management. The essence and advantage of sustainable management is that the balance of the destination is not disturbed, the sustainability of the destination is ensured in all three directions: environment, economy, socio-cultural heritage.

The development of tourism should not be encouraged when it harms the natural environment; Tourism should be organized in such a way that the natural environment is protected in the present and in the future. Tourism activities should be integrated with regional conservation programs. Tourism should be organized to meet future needs. Economic achievements are less important than natural environment Development should take into account the region's capacity, culture and traditions. Tourism promotes cult Heritage protection Unlike ecotourism, the term sustainable tourism refers to the functional commitment of society to ensure the protection and preservation of the environment for future generations. These conditions are not just economic and political factors and need to be strengthened by making tough decisions. Any environment has a maximum load limit, exceeding which can cause serious damage and danger from an economic, social and environmental point of view. In order to achieve sustainable development of tourism, it is necessary to take into account the nature and volume of 
tourism activities, taking into account the potential of existing natural and artificial resources.

In countries characterized by high growth rates of tourist flows, there are natural restrictions on the use of resources. Matheson and Val used the concept of "country capacity", which defines the minimum and maximum populations of a particular country based on available resources, to predict the consequences of the growth of the tourism sector. A simple formula has been developed according to which the mismanagement of resources and excessive demand for a particular service leads to the depletion of the resources already mentioned, which makes the popular service less attractive (Miller \& Twining-Ward, 2005). Stuart McMain clarifies the views of the above authors and speaks of the need for a "capacity concept" to protect tourist attractions. Tourist attractions have limits on customer acceptance. For example, if any of them can receive 400 visitors a day, accommodating relatively more visitors will have a negative impact (Mcminn, 1997). The mass movement of tourists across the country is putting pressure not only on cultural but also on ecological and social issues. For example, a damaged ecosystem can no longer regenerate because it is actively occupied by travelers. Both the area and frequency of contamination increase. Entertainment venues created by small tourism businesses often cause dissatisfaction among locals, leading to conflict (Theobald, 2005). In summary, the mass influx of tourists damages not only different types of structures or ecosystems, but also the image of a particular landmark, reducing demand in the long run causes. The results of the research of Nursat Jahan and Sabrina Rahman can be used to confirm the above opinion. According to a quantitative study conducted by them to identify the factors affecting sustainable tourism in Bangladesh, the active use of cultural monuments and a kind of "tourist nature" and the lack of protection mechanisms have gradually reduced the degree of attractiveness of tourist attractions.

Sustainable tourism is based on three main principles: first is quality; Sustainable tourism should provide quality experiences for visitors, along with improving the quality of life of the host community and protecting the quality of the environment (Inskeep, 1991). The second basic principle is continuity; Sustainable tourism requires the continuity of the resources on which tourism is based; As well as the continuity of the culture of the host community and the continuity of visitor support or tourist demands (Wall, 1993); Finally, sustainable tourism is about balance, it is tourism that balances the needs of the host, guest and host environment (Bramwell \& Lane, 1993; Irrational use can deplete nature's ability to regenerate itself, especially in the case of forest massifs, the degradation of which has many negative environmental consequences.

Tourism and environmental conditions are interrelated. The environment contains many elements. The most important factor in achieving sustainable development is the development and management of tourism in a way that does not harm the environment. Ecologically correct planning of tourism should be well aware of the potential impacts that follow the development of tourism. Sustainable development means balancing economic progress, social justice and protection of the physical and natural environment. The principle of sustainability includes the ecological, economic and socio-cultural aspects of tourism development, so it is necessary to balance all three directions to guarantee the longterm sustainability of the destination.

\section{REFERENCES:}

Azmaiparashvili, M. (2017). Eco-Tourism Potential in Protected Areas and its Sustainable Development Challenges. European Journal of Hospitality and Tourism Research, 5(1).

Devadze, N. (2019). Problems of sustainable tourism development and the main directions of their solution. Batumi.

European Tourism Indicators System for sustainable destination management (ETIS). (2016).

Gigauri, G., \& Supatashvili, A., (2007). Resort-recreational-tourist-importance of Georgian forests and the basics of running a farm in them. Monograph. Tbilisi.

Gulisashvili, V. (1977). Nature and Natural Zones of Georgia. Tbilisi. Soviet Georgia.

Guntsadze, M., \& Tsakadze, V. (2013). Statistical Publication. Georgia's natural resources and environmental protection. Tbilisi. National Statistics Office of Georgia. www.geostat.ge.

https://ec.europa.eu/growth/sectors/tourism/offer/sustainable/indicators_en

Khidesheli, G. (2019). Challenges of Sustainable Tourism Development. Tbilisi.

Kikodze, A., \& Gokhelashvili, R. (2007). Protected Areas of Georgia. Tbilisi. Department of Protected Areas of Georgia.

Macharashvili, I., Arveladze, T., Svanidze, I., Archuadze, M., Kobakhidze, D., \& Kutateladze, I. (2018). Biodiversity monitoring in protected areas. A fierce alternative. http://greenalt.org/wp-content/uploads/2018/07/biodiversity_monitoring_2018.pdf

Metreveli, M. (2012). Environment and Ecotourism Management. Tbilisi. Favorite print.

Ministry of Environment Protection and Agriculture of Georgia. (1996). Law of Georgia on the System of Protected Areas. Tbilisi. Ministry of Environment Protection and Natural Resources of Georgia. Data Research Group. (2017). Visit Survey of Georgian

National Reserves. http://drg.com.ge/team.php

Mowforth, M., \& Munt I. (2016). Tourism and Sustainability, Development, globalization and new tourism in the Third World. Ukleba, M. (2017). Tourist Destination Management. Tbilisi. Wagon.

Visitor statistics by years. (2021). https://apa.gov.ge/en/statistika/vizitorta-statistika/vizitorta-statistika-wlebis-mixedvit. Zazanashvili, N. (1997). Present and Future of Protected Areas of Georgia. Tbilisi. 